\title{
Examination of HIP for production of high density UN kernels
}

\section{Fuel Cycle Research \& Development Advanced Fuels Campaign}

JW McMurray

JO Kiggans

KA Terrani

\section{Prepared for \\ U. S. Department of Energy Office of Nuclear Energy}

April 2017

M3FT-17OR020201056

Approved for public release. Distribution is unlimited. 


\section{DISCLAIMER}

This information was prepared as an account of work sponsored by an agency of the U.S. Government. Neither the U.S. Government nor any agency thereof, nor any of their employees, makes any warranty,

expressed or implied, or assumes any legal liability or responsibility for the accuracy, completeness, or usefulness, of any information, apparatus, product, or process disclosed, or represents that its use would not infringe privately owned rights. References herein to any specific commercial product, process, or service by trade name, trade mark, manufacturer, or otherwise, does not necessarily constitute or imply its endorsement, recommendation, or favoring by the U.S. Government or any agency thereof. The views and opinions of authors expressed herein do not necessarily state or reflect those of the U.S. Government or any agency thereof. 
ORNL/TM-2017/155

Revision 4

\title{
Examination of HIP for production of high density UN kernels
}

\author{
JW McMurray \\ JO Kiggans \\ KA Terrani
}

April 2017

Prepared by

OAK RIDGE NATIONAL LABORATORY

Oak Ridge, TN 37831-6283

managed by

UT-BATTELLE, LLC

for the

US DEPARTMENT OF ENERGY

under contract DE-AC05-00OR22725 

INTENTIONALLY BLANK 


\begin{abstract}
Depleted uranium nitride (UN) kernels with diameters ranging from 420 to 858 microns and theoretical densities between 87 and 91 percent were postprocessed using hot isostatic pressing (HIP) in argon gas. This treatment was shown to increase the TD up to $96 \%$. Uranium nitride is highly reactive with oxygen. Therefore, a novel crucible design was implemented to remove impurities in the argon gas via in situ gettering to avoid oxidation of the UN kernels. Established characterization techniques for determining average weight, volume, and ellipticity of particle fuel was used for calculating the density before and after HIP processing. Micrographs confirm the nearly full densification of the particles using the gettering approach and processing parameters investigated in this work.
\end{abstract}


INTENTIONALLY BLANK 


\section{CONTENTS}

ABSTRACT vi vi

1. INTRODUCTION 1

2. EXPERIMENTAL 2

3. RESULTS AND DISCUSSION 5

4. CONCLUSIONS 7

5. ACKNOWLEDGEMENTS 8

6. REFERENCES 9

\section{FIGURES}

Figure 1. Hot Isostatic Press from American Isostatic Presses, Inc. used in this work to increase the density of the UN microspheres. The HIP is capable of temperatures and pressures up to $2200^{\circ} \mathrm{C}$ and $33 \mathrm{ksi}$ respectively.

Figure 2. Visually oxidized UN kernels from the small batch scoping run without the oxygen gettering crucible.

Figure 3. XRD results for scoping run \#1 without gettering crucible (a) - (c) and with the gettering crucible (d) - (f). The red, blue, and black tick marks correspond to the LaB6 standard, UO2, and UN diffraction angles in that order.

Figure 4. Custom designed HIP crucible made from graphite. The HIP gas must travel a torturous path through hot $\mathrm{Hf}$ or $\mathrm{Zr}$ sponge that binds $\mathrm{O}$ bearing molecules before it enters the sample chamber. There is minimal dead volume above the sample to further reduce the amount of gas and therefore $\mathrm{O}$ impurities that is available to react with the $\operatorname{specimen}(\mathrm{s})$.

Figure 5. Comparison of the sample \%TD's before and after successive HIP processing along with the $95 \%$ confidence interval.

Figure 6. Temperature and pressure versus time plot for HIP run \# 4Figure 7. SEM images of HIP processed 96\% TD FCM-3B-UN14K (a) compared to 89\% TD LEU UN kernels (c) that did not undergo HIP processing (c). Note (d) was taken with an optical microscope to show the voids that are present in the $89 \%$ TD material but that are noticeably absent in the HIPed kernels (b) 


\section{TABLES}

Table 1. Starting size and density analysis with one standard error for the samples used in this study.

Table 2. Manufacturers molar compositional specifications for ultra-high purity Ar

Table 3. Time at the isothermal, isobaric holds for each run 


\section{Examination of HIP for production of high density UN kernels}

\section{INTRODUCTION}

The fully ceramic microencapsulated (FCM) fuel form uses well-developed tri-structural isotropic (TRISO)-coated particles embedded in a dense SiC matrix. The FCM concept leverages existing Light Water Reactor (LWR) infrastructure with an Accident Tolerant (AT) drop-in replacement for $\mathrm{UO}_{2}[1,2]$ However, one challenge is that in an FCM compact much of the U volume has been replaced by TRISO coatings and the $\mathrm{SiC}$ matrix compared to a conventional $\mathrm{UO}_{2}$ pellet since. Due to its high theoretical density (TD), UN is attractive as an FCM fuel kernel and recent neutronics calculations confirm it as a suitable choice for the FCM design [3].

Depleted uranium nitride (UN) microspheres with diameters ranging from 420 to 858 microns and TD between 87 and 91 percent were synthesized in FY15 and FY16 part of a larger effort to explore fabrication routes for Fully Ceramic Microencapsulated (FCM) fuel [4-6]. This work investigates the viability of a post processing step with a hot isostatic press (HIP) shown in Fig. 1 to achieve higher TD to improve their suitability for use as FCM fuel kernels.

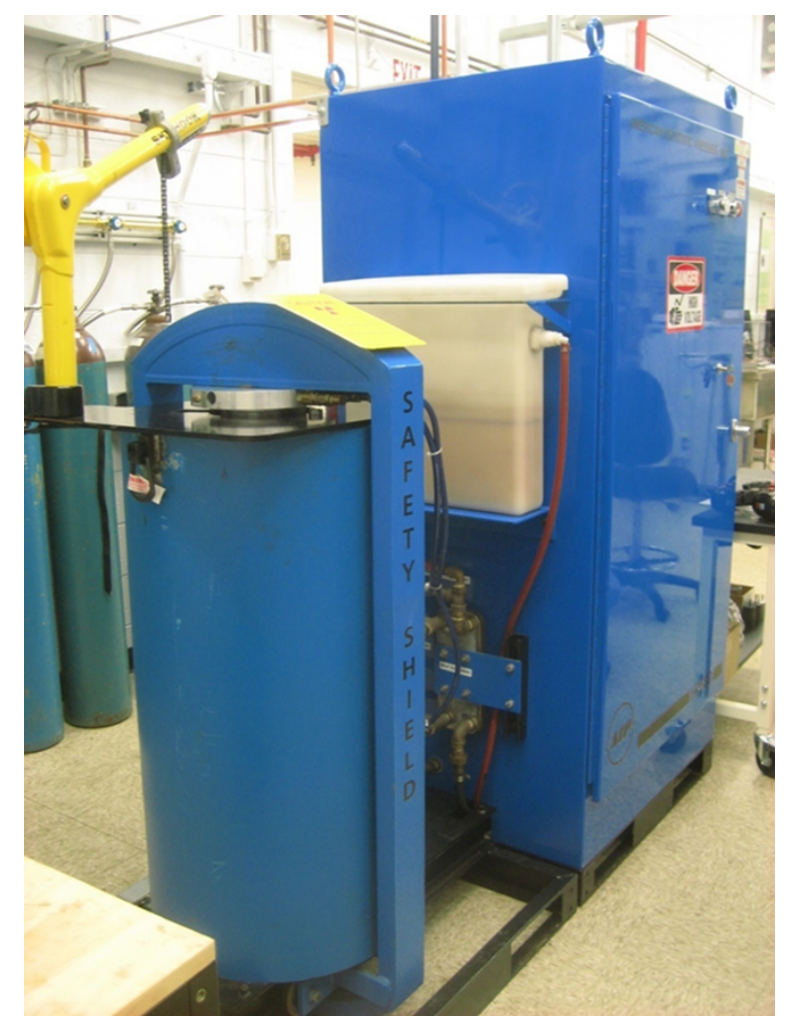

Figure 1. Hot Isostatic Press from American Isostatic Presses, Inc. used in this work to increase the density of the UN microspheres. The HIP is capable of temperatures and pressures up to $2200^{\circ} \mathrm{C}$ and 33 ksi respectively. 


\section{EXPERIMENTAL}

Kernels produced in FY15 and FY16 [6] consistently resulted in between 86-88\% TD UN microspheres with closed porosity. For this work, three different batches, summarized in Table 1, were chosen to investigate increasing density with a HIP post processing step. Preliminary tests on small sample sizes, $\sim 100 \mathrm{mg}$, confirmed suspicions that impurities, particularly $\mathrm{O}_{2}$ and $\mathrm{O}$ bearing vapors (i.e. $\mathrm{CO}, \mathrm{CO}_{2}, \mathrm{H}_{2} \mathrm{O}$ etc.) in the ultra-high purity (UHP) Ar gas HIP media. The Airgas compositional specifications for UHP Ar are given in Table 1. The kernels resulting from the scoping run in are shown in Fig. 2. Phase fractions from X-ray diffraction (XRD) analysis (Fig. 3) determined up to $40 \%$ by mass of the sample was oxidized to $\mathrm{UO}_{2}$.

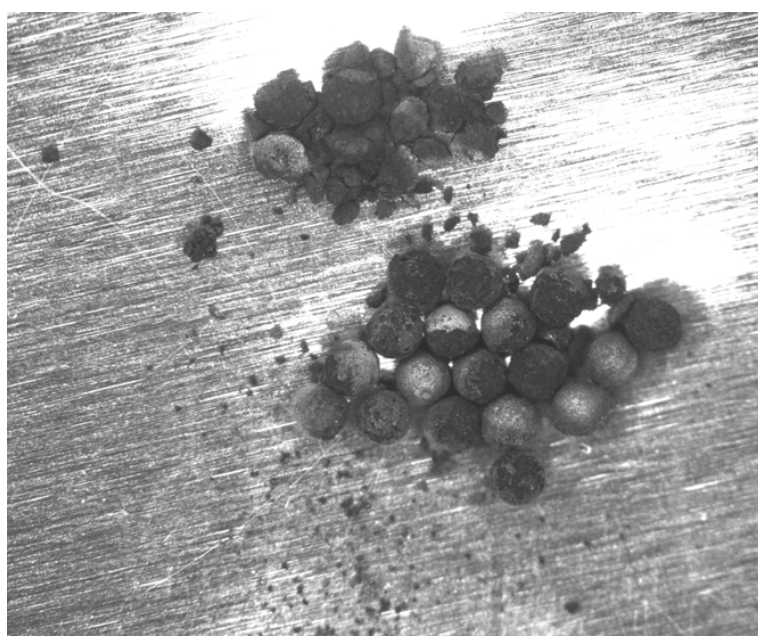

Figure 2. Visually oxidized UN kernels from the small batch scoping run without the oxygen gettering crucible.

Table 1. Starting size and density analysis with one standard error for the samples used in this study.

\begin{tabular}{ccccc}
\hline sample & diameter $(\mu \mathrm{m})$ & density $(\mathrm{g} / \mathrm{cc})$ & $\% \mathrm{TD}$ & $\mathrm{SE}$ \\
\hline FCM UN11 & 828.7 & 12.38 & $87 \%$ & $0.58 \%$ \\
FCM UN17N-K & 858.3 & 12.58 & $88 \%$ & $0.67 \%$ \\
FCM-3B-UN14K & 420.0 & 13.01 & $91 \%$ & $1.38 \%$
\end{tabular}



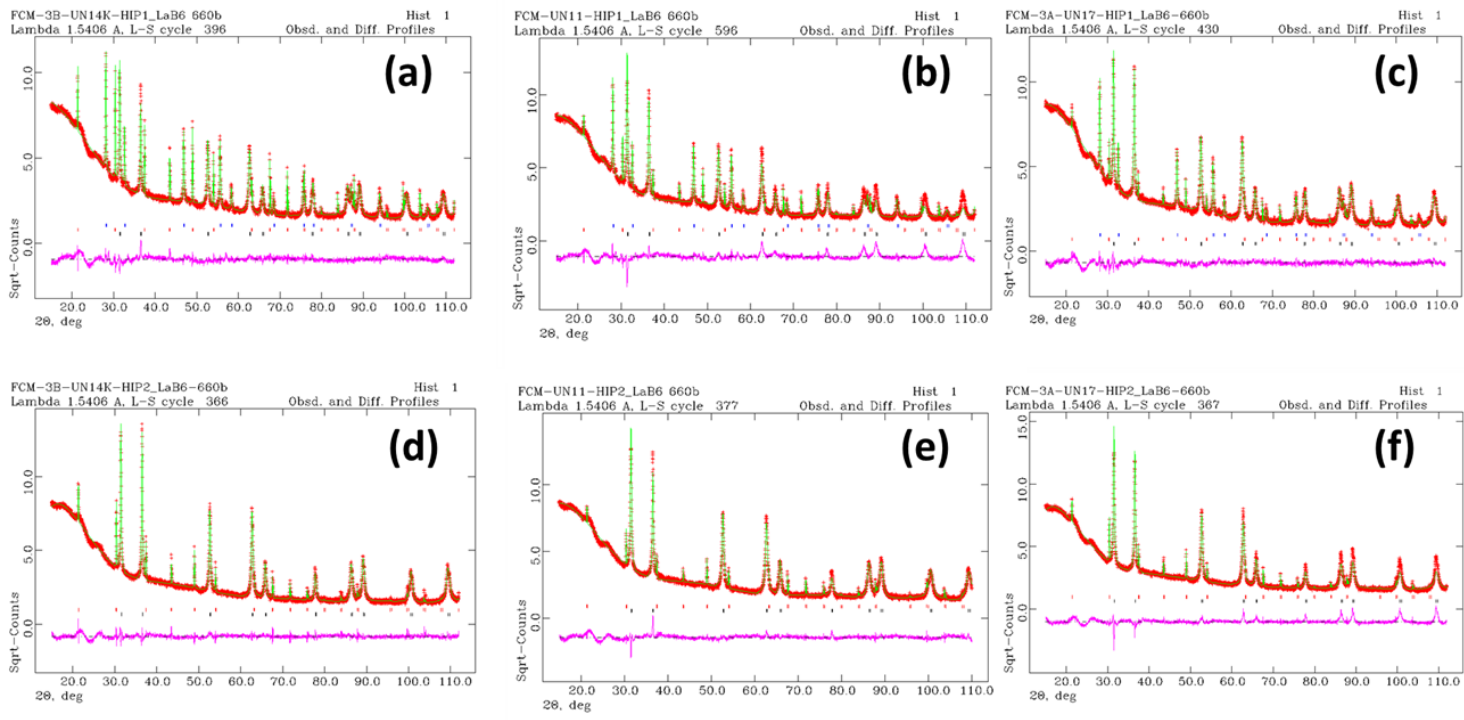

Figure 3. XRD results for scoping run \#1 without gettering crucible (a) - (c) and with the gettering crucible (d) - (f). The red, blue, and black tick marks correspond to the LaB6 standard, UO2, and UN diffraction angles in that order.

While the impurity levels in the UHP Ar given in Table 2 are relatively low, the oxygen potential $\mu_{\mathrm{O}_{2}}$ of the HIP media is always higher than that for $\mathrm{UN}-\mathrm{UO}_{2}$ equilibrium. Therefore, there is always a driving force for $\mathrm{UN}$ oxidation. The progression of the reaction $\mathrm{UN}+\mathrm{O}_{2}=\mathrm{UO}_{2}+1 / 2 \mathrm{~N}_{2}$, however can be made to be kinetically limited via clever equipment design. There are two criteria for this: (1) minimizing volume and (2) reducing the $\mathrm{O}$ bearing impurity levels. Both (1) and (2) are based on the ideal gas law. As pressure goes up, so does the number of gas atoms or molecules in the system. ${ }^{a}$ A custom crucible, shown schematically in Fig. 3, was designed to operate within the $90 \mathrm{~mm}$ diameter by $125 \mathrm{~mm}$ high furnace hot zone of the HIP with the objective of reducing the extent of oxidation to an insignificant degree, i.e. less than 2-3 weight $\%$ and therefore undetectable with X-ray diffraction.

Table 2. Manufacturers molar compositional specifications for ultra-high purity Ar.

\begin{tabular}{cc}
\hline Impurity & Limit \\
\hline Moisture & $<3 \mathrm{ppm}$ \\
$\mathrm{O}_{2}$ & $<2 \mathrm{ppm}$ \\
Hydrocarbons & $<0.5 \mathrm{ppm}$ \\
$\mathrm{CO}_{2}$ & $<1 \mathrm{ppm}$ \\
$\mathrm{CO}_{\mathrm{N}_{2}}$ & $<0.5 \mathrm{ppm}$ \\
& $<5 \mathrm{ppm}$
\end{tabular}

\footnotetext{
a Amount of gas atoms or molecules go down with temperature. In this case the pressure increase effect driving up the amount of gas is much greater in magnitude than that of temperature reducing it.
} 


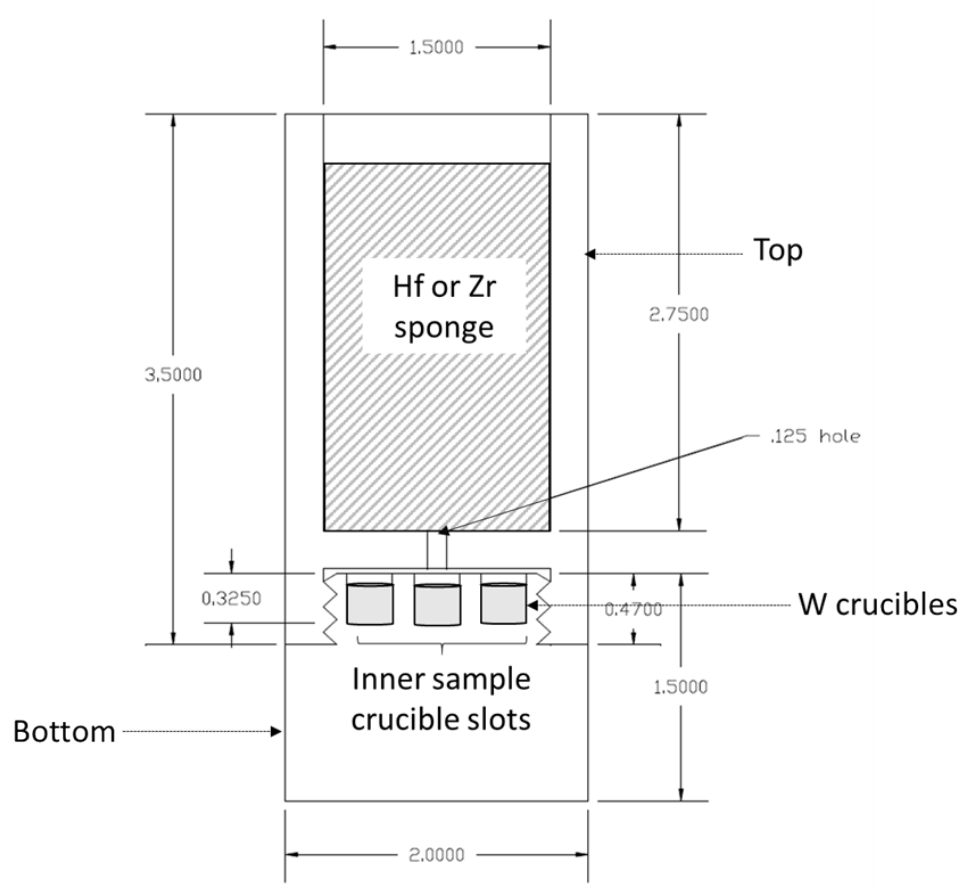

Figure 4. Custom designed HIP crucible made from graphite. The HIP gas must travel a torturous path through hot $\mathrm{Hf}$ or $\mathrm{Zr}$ sponge that binds $\mathrm{O}$ bearing molecules before it enters the sample chamber. There is minimal dead volume above the sample to further reduce the amount of gas and therefore $\mathrm{O}$ impurities that is available to react with the specimen(s).

In the first two small batch $(\sim 100 \mathrm{mg})$ scoping runs, the effectiveness of the crucible at eliminating oxidation was demonstrated. The kernels were intact, with some sporadic color change from grey to black, but otherwise no apparent visual signs of oxidation. The XRD analysis in Fig. 2 show no detectable levels of oxides of uranium. The samples were then successively HIPed and characterized in $\sim 5$ g quantities in runs $3-5$ according to Table 3 .

Table 3. Time at the isothermal, isobaric holds for each run.

\begin{tabular}{cccc}
\hline Run $\#$ & Temperature $\left({ }^{\circ} \mathrm{C}\right)$ & Pressure $(\mathrm{ksi})$ & HIP time (minutes) \\
\hline 1 (scoping) & 1800 & 30 & 100 \\
2 (scoping) & 1800 & 30 & 100 \\
3 & 1800 & 5 & 69 \\
4 & 1800 & 15 & 180 \\
5 & 1800 & 30 & 360
\end{tabular}




\section{RESULTS AND DISCUSSION}

Established characterization techniques for determining average weight, volume, and ellipticity of particle fuel was used for calculating the density (based on the theoretical value for pure UN of $14.3 \mathrm{~g} / \mathrm{cc}$ ) before and after HIP processing; details can be found in [6,7]. The results are plotted in Fig. 5.

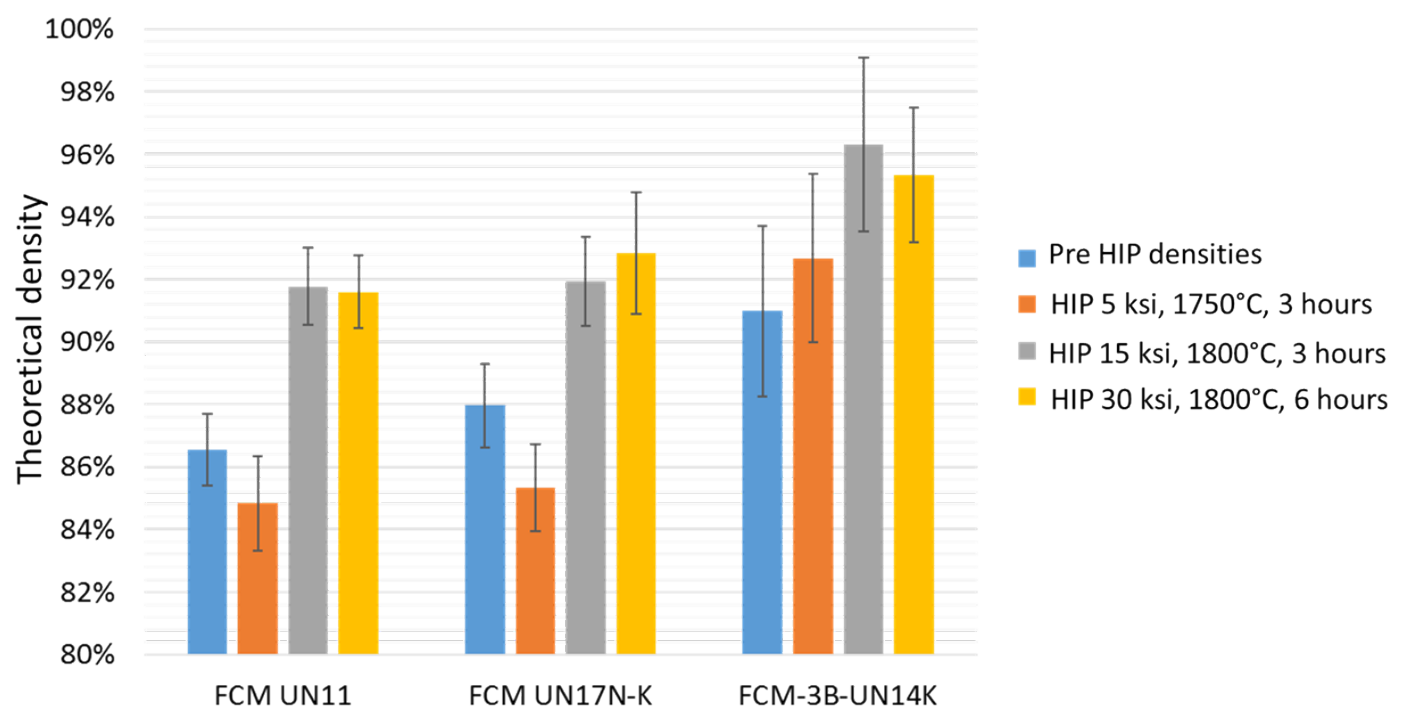

Figure 5. Comparison of the sample \%TD's before and after successive HIP processing along with the $95 \%$ confidence interval.

The HIP processing recipe, shown graphically in Fig. 6, resulted in TD increases from $5-7 \%$. It should be pointed out that the system should not be pressurized until the temperature is sufficient to kinetically activate the getter material thus minimizing ingress of $\mathrm{O}$ bearing impurities into the sample chamber. For that reason, the HIP is vented until $\sim 1000^{\circ} \mathrm{C}$. Pressurization begins thereafter. 


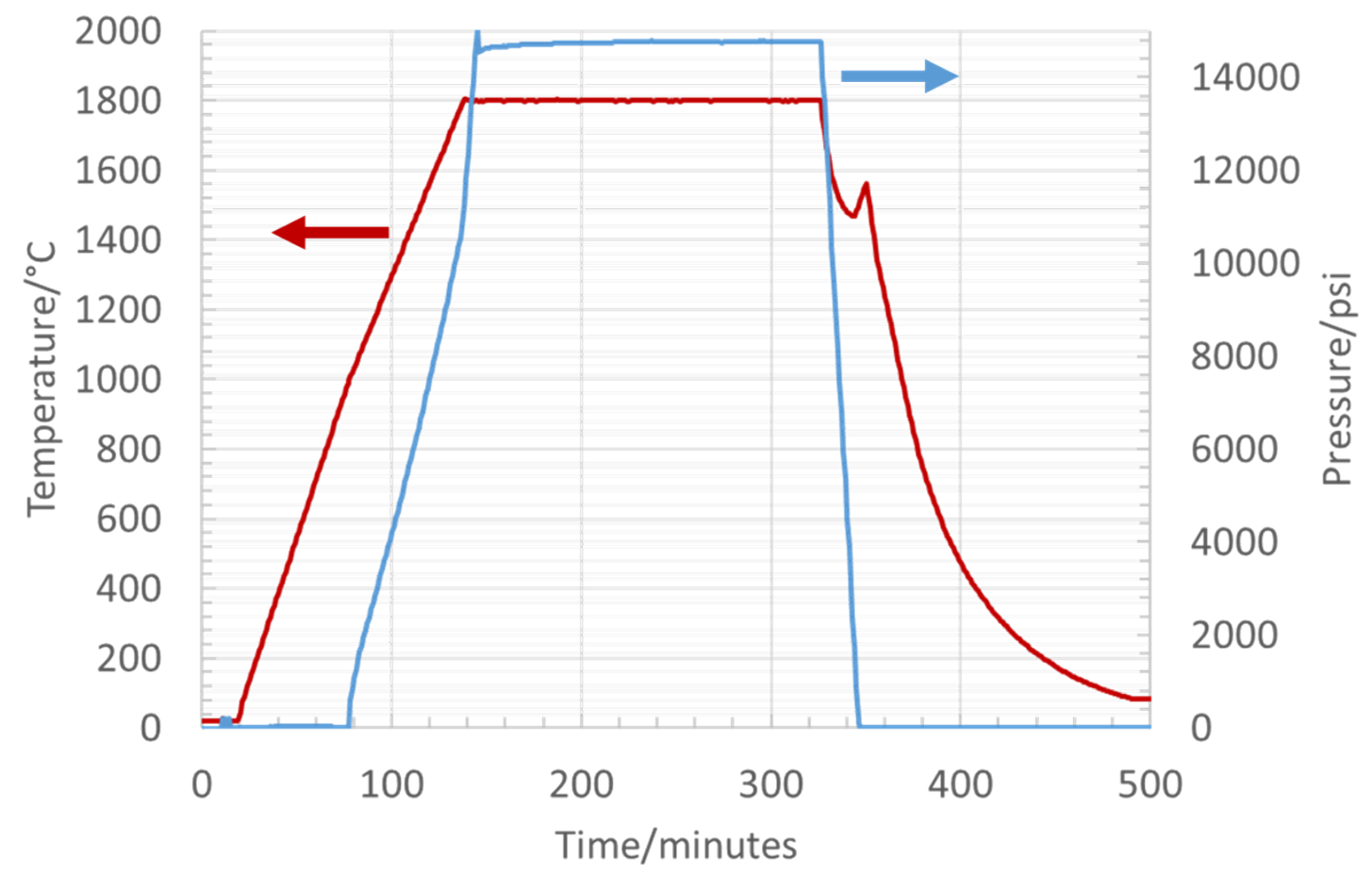

Figure 6. Temperature and pressure versus time for HIP run \# 4.

The final density was dependent upon the starting density and/or particle size. Higher HIPed TD resulted from the smaller $\sim 420 \mu \mathrm{m}$ kernels that were initially chemically converted to $91 \% \mathrm{TD}$ at atmospheric pressures, however, the increase in TD was only $\sim 5 \%$. For the larger $\sim 850 \mu \mathrm{m}$ kernels, larger increases in TD of $6-7 \%$ were observed but the starting densities were lower at 88 and $87 \%$ TD. The micrographs in Fig. 7 confirm the nearly full densification of the 96\% TD particles using the gettering approach and processing parameters investigated in this work. At least one previous study [8] showed cold pressed UN powder could be densified to $97 \%$ TD with a HIP in a tantalum can at $1500^{\circ} \mathrm{C}$ and $10 \mathrm{ksi}$; however, this work demonstrates successful HIP processing of a closed porosity highly reactive material, i.e. UN, using in situ oxygen gettering of the HIP media enabled by an innovative crucible design. 


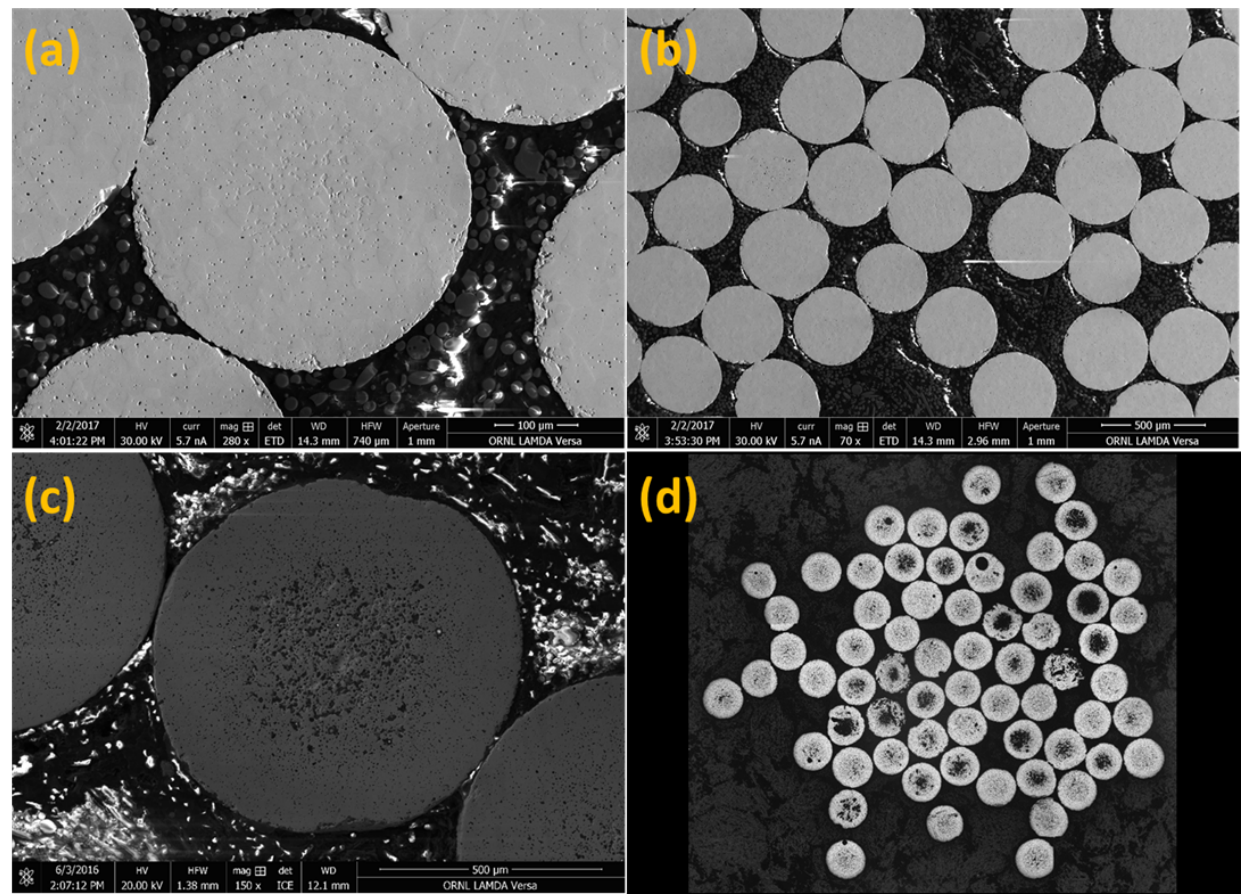

Figure 7. SEM images of HIP processed 96\% TD FCM-3B-UN14K (a) compared to 89\% TD LEU UN kernels (c) that did not undergo HIP processing. Note (d) was taken with an optical microscope to show the voids that are present in the $89 \%$ TD material but that are noticeably absent in the HIPed kernels (b).

\section{CONCLUSIONS}

Hot isostatic pressing of closed porosity UN microspheres with in situ gettered Ar HIP media is effective at increasing the TD up to $97 \%$. Their initial density and size, or both impacted the results. The $\sim 420 \mu \mathrm{m}$ diameter kernels starting at 91\%TD achieved 96\%TD while those that started at 87 and $88 \% \mathrm{TD}$ with $\sim 850 \mu \mathrm{m}$ diameters only attained $92 \% \mathrm{TD}$. In situ gettering of $\mathrm{O}$ bearing vapors is crucial for successful HIP processing; otherwise oxidation occurs and destroys the integrity of the kernels. A crucible design was implemented and proven to reduce $\mathrm{O}$ impurities and enable increasing the density of closed porosity UN microspheres with a HIP. The crucible design can be broadly applied for hot isostatic pressing of closed porosity reactive materials in general. Processing with a HIP at $1800^{\circ} \mathrm{C}$ and $15 \mathrm{ksi}$ for 3 hours was sufficient to achieve measurable increases in TD. Longer HIP times at higher pressures, i.e. $30 \mathrm{ksi}$ and 6 hours, did not result in statistically significant density increases. Future work should investigate the effect of increasing temperature up to $2200^{\circ} \mathrm{C}$ on UN densification with HIP processing. 


\section{ACKNOWLEDGEMENTS}

The authors are grateful to Brian Jolly and Michael Trammell at ORNL for valuable critiques and to Rachel Seibert and Grant Helmreich for technical support and insight. The work presented in this paper was supported by the Advanced Fuels Campaign of the Fuel Cycle R\&D program in the Office of Nuclear Energy, US Department of Energy. 


\section{REFERENCES}

1. Terrani, K.A., et al., Fabrication and characterization of fully ceramic microencapsulated fuels. Journal of Nuclear Materials, 2012. 426(1): p. 268-276.

2. Terrani, K.A., L.L. Snead, and J.C. Gehin, Microencapsulated fuel technology for commercial light water and advanced reactor application. Journal of Nuclear Materials, 2012. 427(1): p. 209224.

3. George, N.M., et al., Neutronics studies of uranium-bearing fully ceramic microencapsulated fuel for pressurized water reactors. Nuclear Technology, 2014. 188(3): p. 238-251.

4. Lindemer, T., et al., Quantification of process variables for carbothermic synthesis of UC 1-x Nx fuel microspheres. Journal of Nuclear Materials, 2017. 483: p. 176-191.

5. Lindemer, T., et al., Carbothermic synthesis of $820 \mu \mathrm{m}$ uranium nitride kernels: Literature review, thermodynamics, analysis, and related experiments. Journal of Nuclear Materials, 2014. 448(1): p. 404-411.

6. $\quad$ Lindemer, T.B., et al., Carbothermic Synthesis of 820- $\mu m$ UN Kernels: Investigation of Process Variables. 2015, Oak Ridge National Laboratory (ORNL), Oak Ridge, TN (United States).

7. Silva, C.M., et al., Characteristics of uranium carbonitride microparticles synthesized using different reaction conditions. Journal of Nuclear Materials, 2014. 454(1): p. 405-412.

8. Speidel, E.O. and D.L. Keller, Fabrication and properties of hot-pressed uranium mononitride. 1963, Battelle Memorial Inst., Columbus, Ohio. 